\title{
Non-tropical endomyocardial fibrosis by cardiovascular magnetic resonance, demonstrating the value of CMR in restrictive cardiomyopathy
}

Christian Hamilton-Craig*, Nicholas J Brett, Jodi Harker, Wendy E Strugnell, Richard E Slaughter

From 2011 SCMR/Euro CMR Joint Scientific Sessions

Nice, France. 3-6 February 2011

\section{Introduction}

Non-tropical non-hypereosinophilic left ventricular endomyocardial fibrosis (EMF) is a rare condition, not associated with defined substrates, about which there is a paucity of data in the literature. We describe a series of EMF patients presenting to our institution over 4 years in a high-volume CMR service.

\section{Purpose}

Retrospective review of 4156 clinical CMR studies (May 2006 to August 2010) was undertaken to identify cases of undifferentiated restrictive cardiomyopathy, confirmed on echocardiography and not otherwise meeting current classification guidelines. CMR had been ordered to further elucidate the etiology of restrictive cardiomyopathy. Obtained metrics were compared to a cohort of age-matched controls.

\section{Methods}

CMR was performed on $1.5 \mathrm{~T}$ system, and dual-read by a cardiologist and radiologist with SCMR level 3 experience. LV volumes, EF, segmental wall thickness, and late gadolinium enhancement were quantified with MASS software. Cases consistent with endomyocardial fibrosis (EMF) were identified and compared to age-matched controls. No patients had history of hypereosinophilia and none were from endemic areas in subtropical Africa.

\section{Results}

5 cases $(0.12 \%)$ of undifferentiated restrictive cardiomyopathy with distinctive features of EMF were identified. ECG was non-diagnostic in all cases, and echocardiography thought to represent the apical form of HCM. Mean age 43 years (range 16-60), 40\% female. Mean EF 50\%

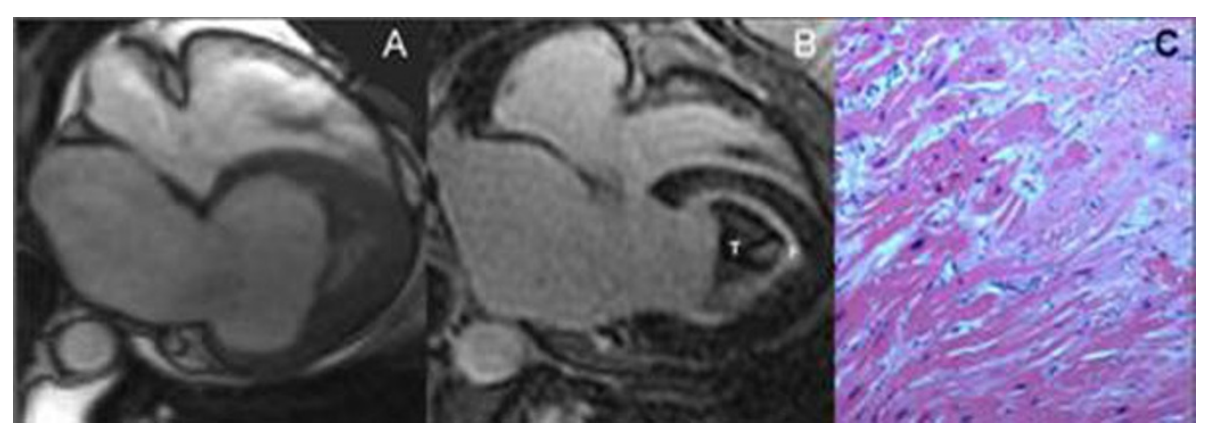

Figure 1 Left Ventricular Endomyocardial Fibrosis A) 4-chamber SSFP, B) LGE showing thrombus (T) and fibrosis (F), C) histologic confirmation.

Centre of Excellence in Cardiovascular MRI, Brisbane, Australia

(c) 2011 Hamilton-Craig et al; licensee BioMed Central Ltd. This is an open access article distributed under the terms of the Creative 
(range $39-59 \%)$, controls $61 \% \pm 2.1(\mathrm{p}=0.020)$. Indexed LV mass was significantly increased $\left(65.6 \pm 2.6 \mathrm{~g} / \mathrm{m}^{2}\right.$ vs $\left.46 \pm 12 \mathrm{~g} / \mathrm{m}^{2}, \mathrm{p}=0.012\right)$, LV length was significantly shorter $(62.2 \pm 13.2 \mathrm{~mm}$ vs $93.5 \pm 5.1 \mathrm{~mm}, \mathrm{p}=0.0005)$, and LV apical wall thickness was significantly increased $(17 \pm$ $6.6 \mathrm{~mm}$ vs $2.5 \pm 0.5 \mathrm{~mm}, \mathrm{p}=0.003)$. All cases of EMF demonstrated extensive, high-signal subendocardial enhancement in the left ventricle on LGE images. Apical thrombus was present in all cases, but only seen on echo in two. Two patients underwent surgery with histological confirmation of CMR findings. Figure 1.

\section{Conclusions}

Non-tropical EMF is distinguished by contracted left ventricular length, increased apical wall thickness, abnormally intense subendocardial fibrosis and presence of apical thrombus. The ventricular architecture and pattern of enhancement differed from the major alternative diagnoses, such as apical hypertrophic cardiomyopathy, left ventricular noncompation and infiltrative myocardial disorders. CMR adds value in the diagnosis of restrictive cardiomyopathies, over-and-above ECG and echocardiography, and can be recommended in cases where ECG and echo data are discordant.

Published: 2 February 2011

doi:10.1186/1532-429X-13-S1-P281

Cite this article as: Hamilton-Craig et al:: Non-tropical endomyocardial fibrosis by cardiovascular magnetic resonance, demonstrating the value of CMR in restrictive cardiomyopathy. Journal of Cardiovascular Magnetic Resonance 2011 13(Suppl 1):P281.
Submit your next manuscript to BioMed Central and take full advantage of:

- Convenient online submission

- Thorough peer review

- No space constraints or color figure charges

- Immediate publication on acceptance

- Inclusion in PubMed, CAS, Scopus and Google Scholar

- Research which is freely available for redistribution

Submit your manuscript at www.biomedcentral.com/submit
C Biomed Central 